\title{
THE EFFECTS OF HORMONES ON BONE IN GROWING RATS
}

\author{
E. TApp, Manchester, England \\ From the Department of Pathology, University of Liverpool
}

Hormones have been shown to have an effect on bone growth and to influence the process of bone formation and resorption, but there is still some difference of opinion about their precise effects. In a previous report (Tapp 1966) it was shown that tetracycline labelling methods are of value in detecting changes in these processes. The same method has been used to re-examine the effect of various hormones on bone. Other workers have shown that relatively high levels of hormone are required to produce bone changes in the rat. These doses are not physiological, and this must be taken into consideration in interpreting the results.

\section{METHOD}

The experiments were carried out on eight groups of rats, each group consisting of five animals. The rats were twenty-eight days old at the beginning of the experiment and they were killed when forty-two days old. Seven groups received one of the following substances daily for fourteen days by subcutaneous injection, the dose indicated being that for each animal of the group each day. Group 1: no injection. Group 2: oestradiol benzoate 0.75 milligram in 0.3 millilitre saline. Group 3 : testosterone propionate 2 milligrams in 0.4 millilitre saline. Group 4: cortisone acetate 2 milligrams in 0.4 millilitre saline. Group 5: thyroxine sodium 50 micrograms in 0.5 millilitre saline. Group 6: thyroxine sodium 5 micrograms in 0.5 millilitre saline. Group 7: neomercazole 5 milligrams in 0.5 millilitre saline. Group 8: beef growth hormone (Armour) 2 milligrams in 0.5 millilitre saline.

Measurements of the rate of growth of the tibia-The rate of growth in length at the proximal epiphysis between the thirty-eighth and fortieth day and the rate of growth in width between the twenty-eighth and fortieth day were determined using the tetracycline labelling methods described before (Tapp 1966).

Histological methods and measurements-Blocks of the upper end of the tibia were decalcified and embedded in paraffin wax. Sections cut longitudinally in the mid-coronal plane were stained with haematoxylin and eosin. The thickness of the epiphysial cartilage and the distance to which the primary bone trabeculae extended from the epiphysial line was measured in these sections.

\section{RESULTS}

Rate of growth of the tibia-The results of the measurements in the different groups are given in Table I. Although the number of animals used in each group is small it will be appreciated from the standard deviations that the findings are very consistent in each group. From this table it is seen that the administration of doses of oestrogen, cortisone or neomercazole resulted in considerable retardation of growth both in width and in length. Large doses of thyroxine also retarded growth but small doses of thyroxine had the opposite effect.

Histological studies and measurement-The results of the measurement on the histological sections are given in Table II. It can be seen that the administration of oestrogen, 50 micrograms of thyroxine or cortisone resulted in thinning of the epiphysial cartilage whereas growth hormone had the opposite effect. The most marked changes in the metaphysis occurred in the oestrogen treated animals where the distance to which the primary trabeculae extend from the epiphysial line was increased. In addition the primary trabeculae were wider and more irregular than in the control animals (Figs. 1 and 2). There were fewer osteoblasts than 
normal, while osteoclasts were present near the epiphysial line but scanty in the deeper part of the metaphysis. Marked changes were also present in the metaphysis of the animals given 50 micrograms of thyroxine. The primary trabeculae were considerably shorter than normal, narrow and irregular, and the marrow cavity extended up to the epiphysial line in some places (Fig. 3).

TABLE I

Rate of Growth of the TiBia

\begin{tabular}{|c|c|c|c|c|c|}
\hline & & $\begin{array}{c}\text { Rate of increase } \\
\text { in length at the } \\
\text { proximal epiphysis } \\
\text { (millimetres } \\
\text { per day) }\end{array}$ & $\begin{array}{l}\text { Standard } \\
\text { error }\end{array}$ & $\begin{array}{c}\text { Rate of increase } \\
\text { in cross-section } \\
\text { (square millimetres } \\
\text { per day) }\end{array}$ & $\begin{array}{l}\text { Standard } \\
\text { error }\end{array}$ \\
\hline Control animals & & $0 \cdot 19$ & \pm 0.009 & 0.025 & 0.001 \\
\hline Oestrogen treated animals. & . & $0 \cdot 12$ & \pm 0.008 & 0.014 & \pm 0.001 \\
\hline Testosterone treated animals & 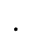 & $0 \cdot 20$ & \pm 0.000 & 0.023 & $\therefore 0.001$ \\
\hline Cortisone treated animals . & . & $0 \cdot 15$ & \pm 0.009 & 0.020 & $\therefore 0.002$ \\
\hline $\begin{array}{c}\text { Thyroxine } \\
\text { animals }\end{array}$ & & $0 \cdot 12$ & \pm 0.005 & 0.017 & $=0.002$ \\
\hline 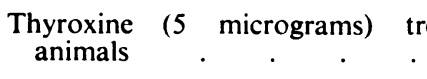 & & $0 \cdot 23$ & \pm 0.010 & 0.035 & $\therefore 0.002$ \\
\hline Neomercazole treated animals & . & $0 \cdot 16$ & \pm 0.013 & 0.014 & $=0.002$ \\
\hline Growth hormone treated animals & . & 0.24 & \pm 0.004 & 0.032 & $\div 0.003$ \\
\hline
\end{tabular}

TABLE II

Measurement on the Histological Specimens

\begin{tabular}{|c|c|c|c|c|c|c|}
\hline & & & $\begin{array}{l}\text { Thickness of } \\
\text { epiphysial } \\
\text { cartilage } \\
\text { (millimetres) }\end{array}$ & $\begin{array}{l}\text { Standard } \\
\text { error }\end{array}$ & $\begin{array}{l}\text { Length of zone of } \\
\text { primary trabeculae } \\
\text { in metaphysis } \\
\text { (millimetres) }\end{array}$ & $\begin{array}{l}\text { Standard } \\
\text { error }\end{array}$ \\
\hline Control animals & & . & $0 \cdot 35$ & $=0.02$ & $0 \cdot 38$ & $\therefore 0.04$ \\
\hline Oestrogen treated animals & . & . & 0.22 & \pm 0.01 & 0.73 & $\pm 0 \cdot 12$ \\
\hline Testosterone treated animals & . & . & 0.36 & \pm 0.02 & $0 \cdot 36$ & 0.02 \\
\hline Cortisone treated animals & . & . & $0 \cdot 32$ & \pm 0.01 & $0 \cdot 39$ & $\therefore 0.06$ \\
\hline Thyroxine ( 50 micrograms) tr & ted & mals & $0 \cdot 25$ & \pm 0.01 & $0 \cdot 27$ & $\therefore 0.02$ \\
\hline Thyroxine (5 micrograms) tre & $\mathrm{da}$ & nals & $0 \cdot 37$ & \pm 0.01 & $0 \cdot 39$ & 0.02 \\
\hline Neomercazole treated animal & . & . & $0 \cdot 33$ & $\div 0.02$ & $0 \cdot 35$ & $\div 0.03$ \\
\hline Growth hormone treated anir & & . & $0 \cdot 42$ & $\div 0.02$ & $0 \cdot 42$ & \pm 0.04 \\
\hline
\end{tabular}

In the cortisone treated animals, although the primary trabeculae extended for a normal distance from the epiphysial line, the trabeculae were wider than normal. In the neomercazole treated animals the primary trabeculae were only slightly shorter than normal but few trabeculae were present (Fig. 4). In animals treated with growth hormone the primary trabeculae were slightly longer than normal but there was no other histological abnormality.

vol. $48 \mathrm{~B}$, No. 3, AUGUST 1966 


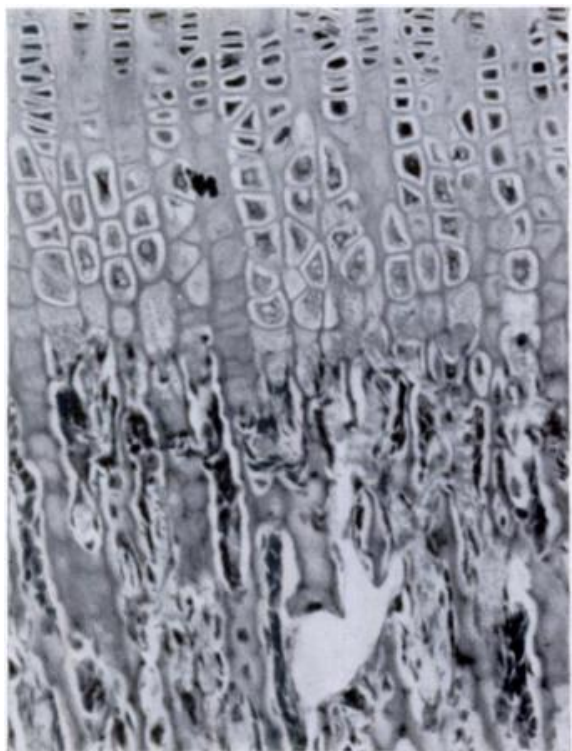

Fig. 1

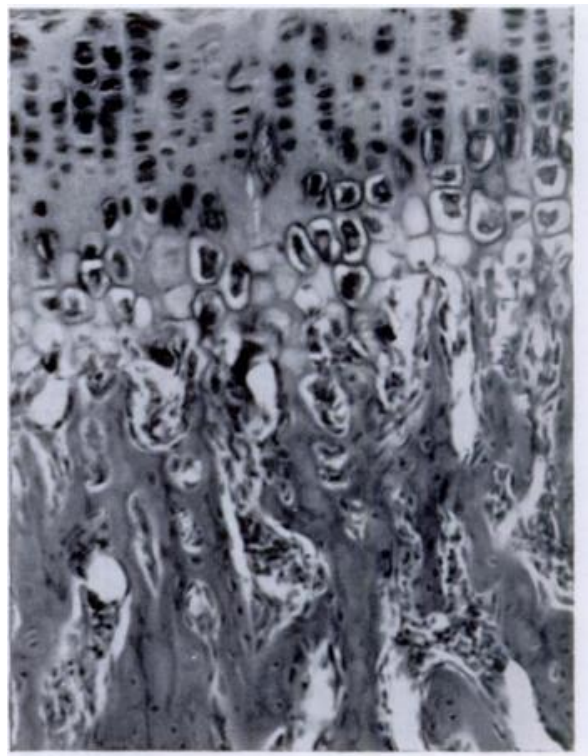

Fig. 2

Figure 1-Photomicrograph of the epiphysis of a control rat of 42 days. The primary trabeculae are regular and are lined by osteoblasts. (Haematoxylin and eosin, $\times 150$.) Figure 2 Photomicrograph of the epiphysis of a rat of 42 days after treatment with oestrogen for fourteen days. The trabeculae are wider and more irregular than in the control animals. (Haematoxylin and eosin, $\times 150$.)

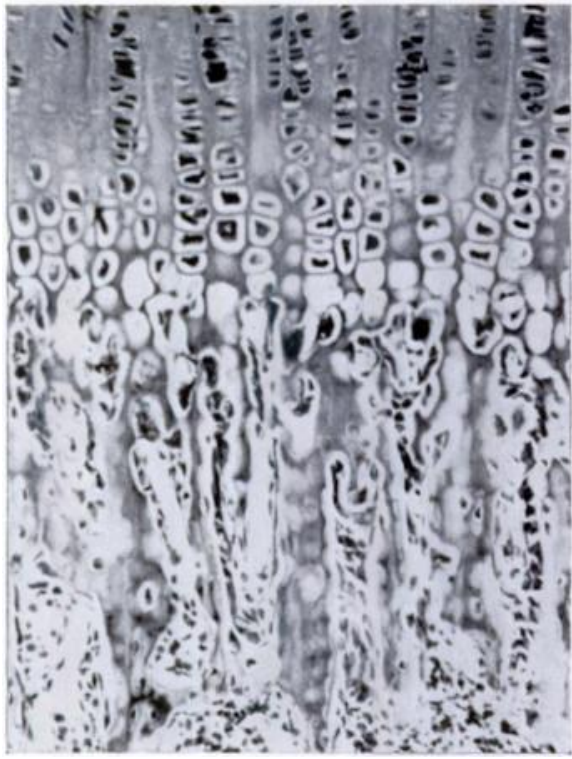

FiG. 3

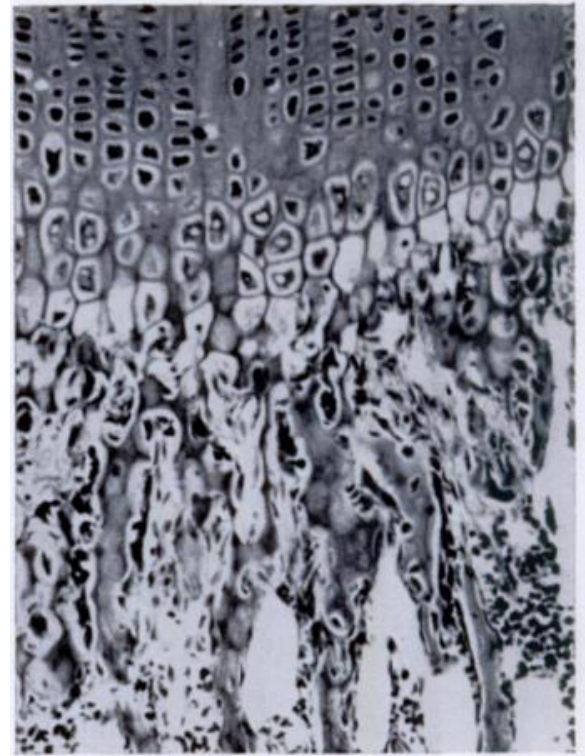

Fig. 4

Figure 3-Photomicrograph of the epiphysis of a rat of 42 days after treatment with 50 micrograms of thyroxine for fourteen days. The trabeculae are considerably shorter than in the control animals and the marrow cavity extends almost to the epiphysial line. (Haematoxylin and eosin, $\times 150$.) Figure 4-Photomicrograph of the epiphysis of a rat of 42 days after treatment with neomercazole for fourteen days. There are only a few trabeculae present in the metaphysis. (Haematoxylin and eosin, $\times 150$.) 
Weight gain and food consumption-The rate of weight gain and food consumption are given in Table III. The rate of gain in weight of rats treated with oestrogen, cortisone or neomercazole was considerably reduced and this was accompanied by a reduction of food consumption.

TABLE III

The Rate of Weight Gain and Food Consumption

\begin{tabular}{|c|c|c|c|c|}
\hline & $\begin{array}{l}\text { Gain in weight } \\
\text { (grams per day) }\end{array}$ & $\begin{array}{c}\text { Food consumption } \\
\text { (grams per day) }\end{array}$ \\
\hline Control animals & . & . & $3 \cdot 4$ & 13 \\
\hline Oestrogen treated animals. & . & . & 1.5 & 9 \\
\hline Testosterone treated animals & . & . & $3 \cdot 6$ & 12 \\
\hline Cortisone treated animals & . & . & $2 \cdot 0$ & 10 \\
\hline \multicolumn{3}{|c|}{ Thyroxine ( 50 micrograms) treated animals } & 1.9 & 12 \\
\hline \multicolumn{3}{|c|}{ Thyroxine ( 5 micrograms) treated animals } & $3 \cdot 4$ & 14 \\
\hline Neomercazole treated anima & $\cdot$ & . & $2 \cdot 2$ & 10 \\
\hline Growth hormone treated ani & & . & 3.9 & 14 \\
\hline
\end{tabular}

On the other hand the animals treated with 50 micrograms of thyroxine also had a reduced rate of gain in weight but had only slightly reduced food consumption.

\section{DISCUSSION}

Effects of hormones on bone formation-Oestrogen, cortisone, 50 micrograms of thyroxine and neomercazole all result in diminished bone formation in the periosteum. A similar result with cortisone has been reported before by Stanisavljevic, Roth, Villanueva and Frost (1962); they also used a tetracycline labelling method. On the other hand previous workers (Day and Follis 1941; Simpson, Kibrick, Becks and Evans 1942; Stahl, Weinmann, Schour and Budy 1950) could not detect changes in periosteal bone formation after the administration of oestrogen, but they only had histological evidence on which to base their findings. The observation that bone formation in the periosteum is reduced in the neomercazole treated rats is not in accord with the recent statement by Hulth and Nylander (1962) that "longitudinal but no appositional growth is diminished " by blockage of thyroid gland secretion. On the other hand the present findings give general support to those of Silberberg and Silberberg (1954) who described diminished periosteal ossification in mice depleted of thyroid function by radioactive iodine. The depression of bone formation in these groups may well be a reflection of the general stunting of the animals as there is a similar reduction in the rate of gain in weight. It was associated with a reduced food consumption in oestrogen, cortisone and neomercazole treated rats although it is interesting to note that this did not occur in the rats given 50 micrograms of thyroxine. Growth hormone and 5 micrograms of thyroxine stimulate bone formation in the periosteum. Thyroxine stimulates growth in thyroidectomised animals and it has been suggested that this occurs through the reinstatement of secretion of growth hormone by the pituitary and by the intensification of the action of growth hormone (Evans, Rosenberg and Simpson 1960). A similar mechanism may account for the stimulation of both somatic and skeletal growth in the animals treated with 5 micrograms of thyroxine in the present study. Although testosterone may stimulate bone growth in humans it does not have any effect on bone formation in the rat. Similar findings have been reported in the past (Turner, Lachmann and Hellbaum 1941; Budy, Urist and McLean 1952). 
Effects on bone resorption-Both oestrogen and cortisone appear to inhibit bone resorption in the metaphysis. In the oestrogen treated animals the primary bone trabeculae are formed at the epiphysial line at only 0.12 millimetre and yet they extend for a distance of 0.73 millimetre. This distance represents six days' growth from the epiphysial line (compared with the normal two days' growth), and indicates considerable reduction in bone resorption. The increased thickness of the trabeculae gives additional support to this concept. Other workers have considered that the excess bone in the metaphysis is due to increased formation of bone (Simpson, Kibrick, Becks and Evans 1942; Barnicot 1951), but this view does not accord with the present findings. Other authors have observed that oestrogens cause increased amounts of bone in the metaphysis of birds, but this cannot be related to the condition in rats because metaphysial bone formation in birds occurs in a cyclical fashion and appears to be partly a calcium storage mechanism for use in egg shell production (Pfeiffer and Gardner 1938).

In the cortisone treated animals, although the primary metaphysial trabeculae are only slightly longer than normal ( 0.39 millimetre), the rate of growth at the epiphysis is only $0 \cdot 15$ millimetre per day, so these trabeculae represent 2.5 days' growth from the epiphysial line. This indicates that bone resorption must be slightly retarded. Histologically the trabeculae are wider than normal. Variation in the amount of bone in the metaphysis in cortisone treated animals was reported by Sissons and Hadfield in 1955. These workers found sclerosis in one group of rats treated with cortisone, while osteoporosis developed in another group. A possible explanation for this variation was given by Storey (1960), who showed that sclerosis of the metaphysis occurs only in rats on a high calcium/phosphate balanced diet; otherwise, osteoporosis tends to develop. Cortisone is known to cause calcium depletion and this could lead to mobilisation from the skeleton presumably through the activity of vitamin D (van Buchem 1959, Storey 1960).

Thyroxine on the other hand appears to cause increased bone resorption in the metaphysis. In the rats treated with 5 micrograms thyroxine a day the primary metaphysial trabeculae are produced at a much higher rate than normal and yet they extend only for a normal distance from the epiphysial line. This may be compared with the effects of growth hormone where the primary trabeculae are also produced at an increased rate but, as growth hormone has no effect on bone resorption, the primary trabeculae extend farther from the epiphysial line than normal. In rats whose thyroid secretion is blocked the rate of growth at the epiphysis is considerably slower than normal, but the primary bone trabeculae in the metaphysis extend for a normal distance from the epiphysial line. It seems that in these rats there must be a reduction in the rate of resorption of bone.

Testosterone did not influence bone resorption in the present experiments.

\section{SUMMARY}

1. In growing rats oestrogen, cortisone and thyroxine in high doses suppress bone formation, and this effect is probably part of a general suppression of body growth.

2. Growth hormone and thyroxine in small doses stimulate both body growth and bone formation.

3. Testosterone has no effect on bone formation.

4. Oestrogen and cortisone suppress bone resorption. The effect of cortisone may be modified in conditions of calcium depletion.

5. Thyroxine appears on the other hand to increase bone resorption.

6. Testosterone has no effect on bone resorption.

I wish to thank Professor H. L. Sheehan for his constant interest and advice during the course of the experimental work and in the preparation of the paper. I also wish to thank Mr Norman Roberts for his helpful criticism. 
REFERENCES

Barnicot, N. A. (1951): The Local Action of Calciferol and Oestradiol on Bone. Journal of Anatomy (London), $85,120$.

van Buchem, F. S. P. (1959): Osteomalacia, Pathogenesis and Treatment. British Medical Journal, i, 933.

Budy, A. M., URIST, M. R., and McLean, F. C. (1952): The Effect of Estrogens on the Growth Apparatus of the Bones of Immature Rats. American Journal of Pathology, 28, 1143.

DAY, H. G., and Follis, R. H., Jun. (1941): Skeletal Changes in Rats Receiving Estradiol Benzoate as Indicated by Histological Studies and Determinations of Bone Ash, Serum Calcium and Phosphatase. Endocrinology, $28,83$.

Evans, E. S., Rosenberg, L. L., and Simpson, M. E. (1960): Relative Sensitivity of Different Biological Response to Thyroxine. Endocrinology, 66, 433.

Hulth, A., and Nylander, G. (1962): Effect of Thyroxine and Propyl Thiouracil on the Epiphyseal Cartilage in Growing Rats. Acta Societatis Medicorum Upsaliensis, 67, 273.

Pfeiffer, C. A., and Gardner, W. U. (1938): Skeletal Changes and Blood Serum Calcium Level in Pigeons Receiving Estrogens. Endocrinology, 23, 485.

Silberberg, R., and Silberberg, M. (1954): Skeletal Effects of Radio-iodine Induced Thyroid Deficiency in Mice as Influenced by Sex, Age and Strain. American Journal of Anatomy, 95, 263.

Simpson, M. E., Kibrick, E. A., Becks, H., and Evans, H. M. (1942): Effect of Crystalline Estrin Implants on the Proximal Tibia and Costochondral Junction of Young Female Rats. Endocrinology, 30, 286.

Sissons, H. A., and Hadfield, G. J. (1955): The Influence of Cortisone on the Structure and Growth of Bone. Journal of Anatomy (London), 89, 69.

Stahl, S. S., Weinmann, J. P., Schour, I., and Budy, A. M. (1950): The Effect of Estrogen on the Alveolar Bone and Teeth of Mice and Rats. Anatomical Record, 107, 21.

Stanisavljevic, S., Roth, H., Villanueva, A. R., and Frost, H. M. (1962): Effect of Adrenal Corticoids on Lamellar Bone Formation Rate in Rat Diaphysis. Henry Ford Hospital Bulletin, 10, 179.

Storey, E. (1960): Bone Changes Associated with Cortisone Administration in the Rat. British Journal of Experimental Pathology, 41, 207.

TAPP, E. (1966): Tetracycline Labelling Methods of Measuring the Growth of Bones in the Rat. Journal of Bone and Joint Surgery, 48-B, 517.

Turner, H. H., Lachmann, E., and Hellbaum, A. A. (1941): Effect of Testosterone Propionate on Bone Growth and Skeletal Maturation of Normal and Castrated Male Rats. Endocrinology, 29, 425. 